\title{
STUDY ON METAL DENTAL MATERIALS IN THE LIGHT OF DENTAL HYGIENE PART II
}

\author{
BY
}

\author{
KAZUO NAGAI*
}

\section{Ccrrosion of Dental Alloys by Means of Electric Current}

As has been described in the Chapter II, in order that diminutions of various dental metals may be known it is necessary to expose the same in such circumstances as fit the purpose. However, for the test of this kind a considerable length of time is required, rendering a test in a comparatively short period impossible. Therefore, for expediting the same test in a limited length of time, Yamamoto $^{91}$, Prof. in College of Technology, Nihon University, devised a simple electrical means with which a corrosion test is conducted on metals. In the following lines, the result of this test is given and as aqueous solutions of acids are the chief means that are required, it is very convenient for the judgment of corrosiveness of dental materials. The test apparatus is composed of the current source (cell battery $6 \mathrm{~V}$ ), variable rheostat, voltmeter and galvanometer, as is shown on Fig. 3 (in the previous issue). A metal to be tested is cut to a specified size and is immersed in solutions with enhancing the electric current progressively from the voltage $\mathrm{O}$ and a variable curve of voltage and current is obtained.

Section 1 Test with ordinary reagents

a. Materials and method

Materials subjected to the present rest included 3 commercial nickel-chrome alloys, 2 nickel-chrome alloys of $\mathrm{Cr} 3 \%, \mathrm{Cr} 4 \%, \mathrm{Cr} 5 \%$ and $\mathrm{Cr} 6 \%, 1$ commercial German silver alloy, various alloys of copper and nickel and amalgam of silver and zinc etc. Reagents were $1 \%$ solution of salt, $0.05 \%$ of chloric acid and $1 \%$ of lactic acid. These materials were used for the test purpose from which were derived the curves of voltage and current. Also the electric density at IV was obtained in an effort to judge the order of corrosiveness of metals under test.

b. Test results

Test results are given on Figs. 4, 5 and 6 .

Table 8 gives the electric density of three reagents used for the test.

Section 2 Test with ordinary drinking water

a. Materials

Metals which were subjected to the test were 14 in number, including silver alloy, $14 \mathrm{~K}$ alloy, alloy of silver and palladium, zinc, copper, nickel, alminum, silver, amalgam, copper alloy for casting, commercial German silver etc. By way

* 永井一夫 Prof. of Dental Technology, Nihon Univ. School of Dentistry 
TABLE 8

Electric Density in $1.0 \mathrm{~V}\left(\mathrm{~mA} / \mathrm{cm}^{2}\right)$

\begin{tabular}{|c|c|c|c|}
\hline Solutions & $1 \%$ salt solution & $\begin{array}{l}0.05 \% \text { hydro- } \\
\text { chloric acid }\end{array}$ & $1 \%$ lactic acid \\
\hline Zinc & 4.1 & 2.28 & 0.91 \\
\hline Copper & 0.94 & 0.83 & 0.57 \\
\hline Nickel & 0.026 & 1.05 & 0.13 \\
\hline Alminum & 4.32 & 2.5 & 1.25 \\
\hline Silver & 0.6 & 0.54 & 0.3 \\
\hline Amlgam & 1.98 & 1.1 & 0.73 \\
\hline Copper alloy for casting & 0.34 & 0.98 & 0.33 \\
\hline Commercial copper alloy & 0.03 & 0.75 & 0.25 \\
\hline Commercial German silver & 0.2 & 0.61 & 0.3 \\
\hline German silver $\begin{cases}\mathrm{Cu} & 60 \% \\
\mathrm{Ni} & 25 \% \\
\mathrm{Zn} & 15 \%\end{cases}$ & 0.26 & 0.79 & 0.26 \\
\hline German silver $\begin{cases}\mathrm{Cu} & 55 \% \\
\mathrm{Ni} & 22 \% \\
\mathrm{Zn} & 15 \%\end{cases}$ & 0.13 & 0.79 & 0.39 \\
\hline 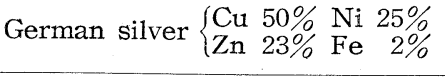 & 0.13 & 0.79 & 0.26 \\
\hline $\begin{array}{l}\text { Commercial nickel-chrome } \\
\text { alloy (A) }\end{array}$ & 0 & 0.26 & 0 \\
\hline $\begin{array}{l}\text { Commercial nickel-chrome } \\
\text { alloy (B) }\end{array}$ & 0 & 0.22 & 0 \\
\hline $\begin{array}{l}\text { Nickel-chrome alloy with } \\
3 \% \text { chrome }\end{array}$ & 0.13 & 1.18 & 0 \\
\hline $\begin{array}{l}\text { Nickel-chrome alloy with } \\
4 \% \text { chrome }\end{array}$ & 0.13 & 1.58 & 0 \\
\hline $\begin{array}{l}\text { Nickel-chrome alloy with } \\
5 \% \text { chrome }\end{array}$ & 0.13 & 1.22 & 0 \\
\hline $\begin{array}{l}\text { Nickel-chrome alloy with } \\
6 \% \text { chrome }\end{array}$ & 0 & 1.45 & 0 \\
\hline Silver alloy & 0.47 & 0.40 & 0.24 \\
\hline
\end{tabular}

of reagents, use was made of sauce, soy sauce, soup of bean paste, beer, fruit juice, sake or rice wine and cider.

b. Results

Figs. 7,8 and 9 respectively give the results of tests under review. As is 
known from them, metals indicate different corrosivenesses according to the different reagents used.

c. Consideration of results

As are shown by Figs. 10, 11 and 12, the order of corrosivenesses of metals is $14 \mathrm{~K}$ alloy, commercial nickel-chrome alloy, silver-palladium alloy, silver, German silver alloy, copper alloy, amalgam, copper, nickel, alminum and zinc. It is found that human saliva also has some corrosive influence upon metals and its strength is considered to be somewhere middle of usual beverages.

\section{Influence of Saliva on Metals in Oral Cavity}

As has been touched on in Sec. 4 of Chap. IV, the oral cavity secretes a considerable quantity of reflex saliva. Therefore, the electric test was conducted in order to see the corrosive influence of saliva on dental metals.

Section 1. Influence of beverages mixed with saliva on zinc.

Fig. 13

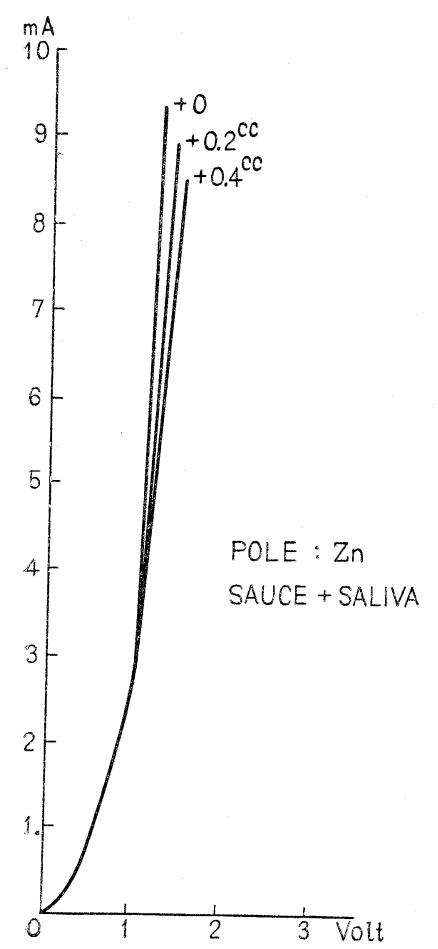

Fgi. 14



Reagents were sauce, beer, $1 \%$ solution of salt, $0.05 \%$ solution of hydrochloric acid etc. To them was added a certain specified amount of saliva and the corrosive influence on them was looked into.

1) Sauce

As the result of addition of saliva, there was observed a decrease in electric current. Saliva is found to have an inhibitory function upon the corrosiveness of sauce.

2) Beer

As is shown on Fig. 14, addition of saliva to beer is found to increase its corrosive function.

3) $0.05 \%$ hydrochloric acid and $0.005 \%$ hydrochloric acid solutions

Addition of saliva to the aqueous solution of $0.05 \%$ hydrochloric acid inhibits the corrosive function (Fig. 15). On the other hand, addition of saliva to 0.005 hydrochloric acid solution enhance the corrosive function (Fig. 16).

Section 2. Influence of total amount of $2 \mathrm{cc}$ saliva on zinc 
Fig. 15

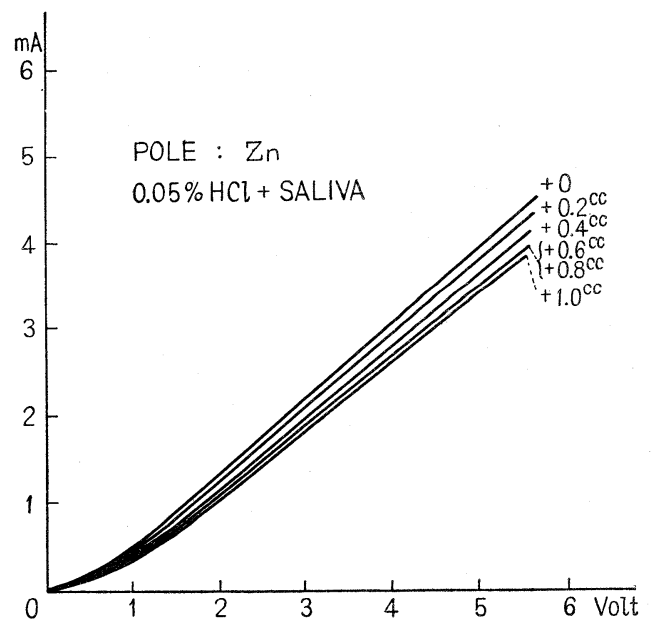

Fig. 17



Fig. 16

As the result of the tests described in the above section, it is found that an addition of saliva proves an inhibitory influence upon beverages the corrosive function of which is strong and, on the other hand, it enhances corrosiveness when beverages are weak in corrosive function.

With the aim of furnishing a further evidence to this conclusion, another series of tests were conducted in which the amount of saliva was made $2 \mathrm{cc}$ with an addition of water and others.

1) $1 \%$ salt solution

Fig. 17 shows an addition of $1 \%$ salt solution to saliva. When compared with Fig. 18 in which plain water is added to saliva, we can find that a decrease in the density of saliva proportionately enhances the corrosive function.

2) $0.0005 \%$ hydrochloric acid solution

A comparison between Figs. 19 and 20 points to a finding that an addition of water to this kind of acid solution lowers its corrosive function and yet it increases in the corrosive function when saliva is added to it.

Section 3. Considerations

Fig. 19

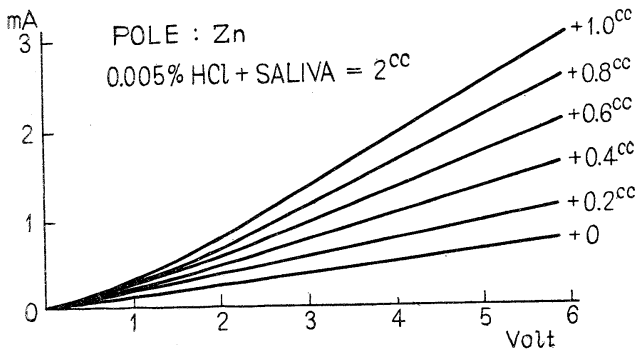

Fig. 20

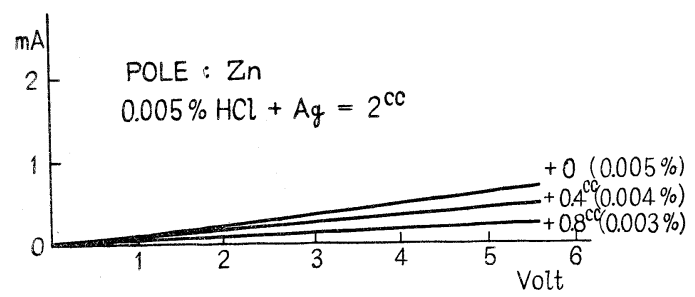

It does not always take place that an addition of saliva to beverages inhibits the corrosive function of them. However, as saliva is an electrolyte of organic character, it will assume the inhibitory influence when it transforms itself into a non-electrolyte substance.

As the result of the series of tests, it has been established that an addition of saliva to beverages with high corrosive function inhibits the same function. On the other hand, it increases the corrosiveness of those beverages which are weak in corrosive function. This also holds true of various reagents such as salt solution and hydrochloric acid solution.

It is an interesting fact in the light of physiology that human saliva which is a physiological secretion exercises an inhibitory function upon dental materials 
in the oral cavity under remarkable circumstances where the corrosiveness is high and thus prevents the inroad of metals into the body by increasing its own secretion.

\section{Observations Regarding Corrosion of Dental Metals in Oral Cavity}

Section 1. Materials and method

As experimental materials, use was made of mature dogs weighing around $15 \mathrm{Kg}$. The four major salivary glands in their mouths were completely ligatured and minor glands were also stopped by means of Paquelin's cautery for the purpose of preventing the flow of salivary secretion. Following the process, the dogs were subjected to the electric current at $80 \mathrm{~V}$ for 50 seconds in an effort to induce the salivary secretion by bringing about a clamp-like movement. In this procedure, the teeth that faced each other were extracted to prevent any friction due to occlusion.

Section 2. Results and their considerations

The results of this test are given on Tables 9 and 10 .

TABLE 9

Diminution due to Corrosion (an Ordinary Dog)

\begin{tabular}{l|c|c}
\hline & Pure copper crown & Pure zinc crown \\
\hline Area & $3.6266 \mathrm{~cm}^{2}$ & $5.4749 \mathrm{~cm}^{2}$ \\
First amount & $3185.4 \mathrm{mg}$ & $3456.6 \mathrm{mg}$ \\
After 30 days & $3159.4 \mathrm{mg}$ & $3453.5 \mathrm{mg}$ \\
Diminution & $25.9 \mathrm{mg}$ & $3.1 \mathrm{mg}$ \\
mg/cm & $7.14 \mathrm{mg}$ & $0.57 \mathrm{mg}$ \\
Diminution per day & $0.23 \mathrm{mg}$ & $0.019 \mathrm{mg}$
\end{tabular}

Talbe 10

Diminution due to Corrosion (a Dog devoid of Saliva)

\begin{tabular}{l|c|c}
\hline & Pure copper crown & Pure zinc crown \\
\hline Area & $3.6250 \mathrm{~cm}^{2}$ & $5.4731 \mathrm{~cm}^{2}$ \\
First amount & $3184.3 \mathrm{mg}$ & $3452.5 \mathrm{mg}$ \\
After 30 days & $3136.3 \mathrm{mg}$ & $3445.7 \mathrm{mg}$ \\
Diminution & $48.0 \mathrm{mg}$ & $6.8 \mathrm{mg}$ \\
mg/cm & $13.24 \mathrm{mg}$ & $1.24 \mathrm{mg}$ \\
Diminution per day & $0.44 \mathrm{mg}$ & $0.041 \mathrm{mg}$
\end{tabular}

As regards the normal dogs, the crowns of pure copper installed on their teeth turned into dark brown after about four days and those of pure zinc turned into gray after the same length of time. The quantities of diminutions per $1 \mathrm{~cm}^{2}$ 
are $7.14 \mathrm{mg}$ and $0.57 \mathrm{mg}$ respectively. As regards the dogs on which operation was conducted in order to stop their salivary secretion, the crowns of pure copper and pure zinc began to assume change in color after two days. After one month, the quantities of their respective diminutions per $1 \mathrm{~cm}^{2}$ are $13.24 \mathrm{mg}$ and $1.24 \mathrm{mg}$. That is to say, the chemical corrosion in the case of the dogs devoid of saliva has advanced as much as twice compared with the normal dogs. This is indicative of the fact that saliva serves the purpose of inhibiting the corrosion on the part of dental metals in the oral cavity. This fact should prove an interesting finding coupled with the conclusion given under Chapter $\mathrm{V}$ above.

Section 3. Behavior of metals in human oral cavity

Two kinds of copper alloys for dental use were employed for the present test. The upper plate was manufactured out of the alloys and installed in the human oral cavity. After 20 days of installation, the amount of diminution per $\mathrm{cm}^{2}$ was measured with the result on Table 11.

TABLE 11

Behavior of Metals in Human Oral Cavities

\begin{tabular}{|c|c|c|c|c|c|c|c|}
\hline Testee & Age & Metal & $\begin{array}{c}\text { First } \\
\text { amount }(\mathrm{g})\end{array}$ & Area $\left(\mathrm{m}^{2}\right)$ & $\begin{array}{c}\text { Days under } \\
\text { test }\end{array}$ & $\underset{(\mathrm{mg})}{\operatorname{Diminution}}$ & $\begin{array}{l}\text { Diminution } \\
\text { per day } \\
\left(\mathrm{mg} / \mathrm{cm}^{2}\right)\end{array}$ \\
\hline $\mathrm{A}$ & 22 & Cu-Alloy 1 & 6.0046 & 25.14 & 20 & 18.6 & 0.0374 \\
\hline B & 22 & $\begin{array}{lll}\prime \prime & \prime \prime & 2\end{array}$ & 4.2815 & 13.20 & 20 & 10.6 & 0.0402 \\
\hline $\mathrm{C}$ & 21 & $\| \quad 113$ & 5.1756 & 15.39 & 20 & 10.1 & 0.0328 \\
\hline $\mathrm{D}$ & 21 & "l $\quad 114$ & 4.7451 & 14.22 & 20 & 8.3 & 0.0292 \\
\hline
\end{tabular}

As is known from these figures, the amount thus diminished is quite negligible with $0.03-0.04 \mathrm{mg}$ per $\mathrm{cm}^{2}$.

Section 4. Conclusions

As is given under Section 2 and 3 above, it has been established that the presence of saliva in the oral cavity of dogs prevents the metals from corroding to a high extent. It is also found that as regards the behavior of dental metals in the human oral cavity, the amount of diminution per day is so small that it can be safely regarded as negligible.

\section{General Discussion and Conclusions}

In the foregoing study, the author has attempted at looking into the behavior of dental metals in the oral cavity from the point of oral hygiene.

1. As a basic step, the corrosiveness of various metal materials due to every-day beverages was looked into. The every-day beverages subjected to the test covered apple juice, orange juice and others. As a result, it has been established that the corrosiveness on their part due to these beverages is quite negligible compared with those of $0.05 \%$ hydrochloric acid, $1 \%$ lactice acid and $1 \%$ salt solution. 
2. As the fact is known that a great deal of saliva is secreted by the consumption of food, a series of test was conducted to obtain the different amounts of reflex saliva according to the kinds of food taken. Consequently, we have come to conclude that a difference in the kind of food produces a variation in the secretion of reflex saliva.

3. When the teeth were subjected to a corrosive test at $37^{\circ} \mathrm{C}$ for 3 days, the following findings were obtained. As regards German silver alloys, corrosion in $0.05 \%$ hydrochloric acid is about 31 times and in 1\% lactic acid corrosion of the same alloys is about 118 times.

The present legal specifications of reagents used for testing the corrosiveness of dental metals seem to be considerably higher in concentration.

4. The findings obtained from a series of tests in which the dogs were made to swallow dental metals on purpose are as follows. After 3 days of having been contained in the stomach of dogs, nickel-chrome alloys, 18.8 steel and $22 \mathrm{~K}$ gold alloy did not show any diminution due to corrosion. Diminution per $\mathrm{cm}^{2}$ daily is $0.24 \mathrm{mg}$ in copper nd $1.37 \mathrm{mg}$ in amalgam respectively. This should be indicative of the fact that metal ion to be produced from these dental metals in the human body exerts no chemical harm physically.

5. As a means of expediting a corrosive test, a simple test by means of electric currents was resorted to. As a result, an interesting fact has been known that the presence of saliva inhibits corrosiveness in connection with certain acids and increases the same function in connection with some other acids.

6. In order to look into the behavior of saliva on dental materials in the oral cavity, a test was carried out in which test dogs were blocked in their salivary ducts with the test materials installed in their mouths for a period of one month. Diminution which was observed in the dogs whose salivary secretion was stopped has advanced as much as twice against that of normal salivary secretion. The amount of diminution per $\mathrm{cm}^{2}$ daily in pure copper installed in the normal dogs is $0.2 \mathrm{mg}$ and that of pure zinc is $0.02 \mathrm{mg}$, both being considered as negligible.

7. The daily diminution of copper alloy in the human oral cavity is anywhere from 0.03 to $0.04 \mathrm{mg} / \mathrm{cm}^{2}$. As the amount is regarded negligible, any harmful influence either locally or totally is out of the question. The same holds true of other metals.

\section{REFERENCES}

9) Yamamoto, Y. : Study on Anti-corrosiveness of Metals, Rikagaku-Kenkyujo-Iho, 19, 3.

10) IWAO, S.: On Substitute Alloy for Gold, Kokubyo-Gakkai-Zasshi, 13, 3.

11) IwAO, S.: On Peculiarity of Dental Treatment and Value of Dental Metals, Nihon-noshikai, 240 .

12) Hanazawa, K. : On Substitute Alloy for Gold, Shika-Gakuho, 44, 1, 2, 3.

13) Tagatani, M., Yamagami, J. and Ibaragi, M.: On Electric Potential of Dental Metals, Nihon-no-shikai, 233.

14) TAgatani, M. and Yamagami, J.: Electro-chemical Character of Dental Metals, A speech delivered at 12 th Conference of Japan Oral Path. Asso.

15) TAgAtAni, M. and IBARAKI, M. : Corrosiveness and Electro-chemical Character of Dental Metals, Nihon-Kinzoku-Kaishi, 4, 3.

16) Tagatani, M. and Yamagami, J.: Corrosiveness of White-colored Alloys with Nickelchrome as Base, Nihon-no-shikai, 221. 
17) NAGAI, K.: Metallurgic Study of A Kind of Nickel-chrome Alloy, Shika-Geppo, 19, 5.

18) NAGAI, K. and IMAZEKI, T.: Vital Reactions of Various Dental Metals, Kyoto-shikagakkai, 25, 4.

19) LEWIN, L. : Gifte und Vergiftung (1929)

20) Yamagami, J. and TAKagami, M. and Terano, H. : Study on Harmful Influence of Nickel-chrome Alloys, Part 1, Nihon-no-shikai, 240.

21) Akatsuka, T. and Fairhall, B.: The Texicology of Chromium, Journal of Industrial Hygiene, 1934.

22) Kunit, H. KASUya, T. Ishida, S. Sakai, M. Kojima, K. and NAKAmura, T.: Relationship between Vital Reactions of Cr-Ni Family Alloys and their Metallurgic Findings, Nihon-shikazairyokikai-gakkai-zasshi, $1,1$.

23) Skinner, W.: The Science of Dental Materials, 1950. 